\title{
The unendangered whale
}

\begin{abstract}
Dr Ray Gambell, of the Whale Research Unit at the British Museum (Natural History), discusses the new rules for whaling adopted by the International Whaling Commission this year and argues against previous calls for a complete moratorium.
\end{abstract}

EVER since the 1972 Stockholm conference on the human environment there has been a persistent call to impose a 10-year ban on commercial whaling. This year's annual meeting of the International Whaling Commission (IWC), held in London in June, again considered this proposed moratorium. The IWC's Scientific Committee advised that because the concept of individual species management is now operative, there is no biological requirement for a blanket ban on all catching, and indeed, catching of some species may be necessary to promote the maximum rebuilding of other depleted stocks because of interspecific competition.

The IWC, which regulates about $90 \%$ of the world's whaling, therefore adopted an amended moratorium proposal which sets out the criteria by which the various whale stocks will be harvested in future. Briefly, these divide whale stocks into three categories; 'protection stocks', which will not be hunted at all; 'sustained management stocks', which can be caught at carefully controlled levels; and 'initial management stocks', which are very abundant and can also be taken in suitably regulated numbers to prevent any risk of overexploitation.

By adopting this regime for future commercial whaling activity, the IWC has effectively placed the regulation of whaling in the hands of its Scientific Committee. This committee is charged with the responsibility of allocating the various whale stocks into the three categories defined above, and then deciding the level of catch which each can sustain if it is available for exploitation. The original Convention for the Regulation of Whaling signed in 1946 was formulated to provide for the conservation, development and optimum utilisation of the whaling resources. This was to be based on scientific findings, but could also take into account the interests of the consumers and the whaling industry. In the past the economic arguments of the latter two groups often outweighed the advice given by the scientists, with the consequent decline of some of the major whale stocks. Now the emphasis has swung very much towards the scientific side. It remains to be seen just how well the scientists can resist the political and economic pressures which up till now have been exerted mainly in the full commission meeting rather than in the Scientific Committee.

The present scheme for the management of the whale resources can be seen as part of the general development of the policy adopted by the IWC in recent years. This is based on the concept of sustainable yield. In a stable, unexploited population the number of new recruits exactly balances the deaths due to natural mortality. When the population size is reduced by whaling, the recruitment rate increases through a lowering in the age at which the animals become sexually mature, and also by an increase in the pregnancy rate. The natural mortality rate also falls as whales are caught before they have a chance to die naturally.

The exact forms of the relationships between the changes in recruitment rate and natural mortality rate with decreasing population size are not known for

Fig. $1 a$, A theoretical relationship between the net recruitment rate and a whale population size. $b$, Sustainable yield at each whale population size derived from the theoretical recruitment relationship.

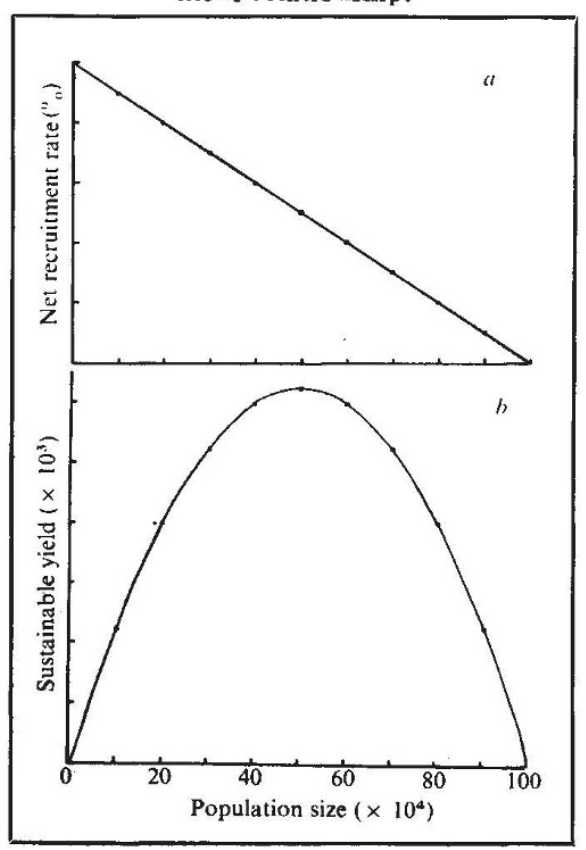

certain in the whales, although there is some evidence from blue, fin and sei whales that the recruitment rate increases linearly. In Fig. 19 such a linear form for the variation in a theoretical net recruitment rate with population size is shown. This represents the gross recruitment by reproduction less the natural mortality. Multiplying every population size by the appropriate net recruitment rate gives a number, plotted in Fig. $1 b$, which is the surplus of recruitment over natural deaths. This surplus is a yield which can be harvested indefinitely without changing the overall population size. As can be seen from Fig. $1 b$, the yield is small in populations which have been much depleted in size. It is also small in those populafions which have been but little reduced. The yield reaches a peak, the maximum sustainable yield (MSY), at some intermediate population size which is generally around half the original population number. Catching the sustainable yield will hold a population at its present level. Catching less than the sustainable yield will mean an addition to the total population size, which will therefore increase in numbers. For a population which is smaller than the level giving the MSY, this will allow some rebuilding towards that level; a population above that level will increase still further. Conversely, catching more than the sustainable yield will deplete the population, and for a population already below the MSY level will make it still less productive.

It is relevant now to consider where the various whale populations stand in relation to their MSY positions. In both major whaling areas, the Southern Hemisphere and the North Pacific, the same species are in very similar states. Blue, humpback and right whales are very seriously depleted and far to the left in the yield diagram (Fig. $1 b$ ). This is why they are totally protected from catching by the IWC. Grey whales in the North Pacific are also protected, although they have recovered from a very low level and now seem to be stabilised near their former original number.

Sei whales are close their MSY levels in both regions, although there are some variations between the component stocks in each case. Male sperm whales are also close to their MSY levels, but the females are relatively unexploited and far to the right of the yield diagram. Antarctic minke whales are also very 
The end of the line.

Copyright: National Institute of Oceanography.

abundant, as they have only been caught in large numbers in the past two seasons.

Fin whales, although a major component of the whaling industry's economy, are only at a third or a half of their MSY levels, and so need to rebuild in both regions.

Since 1965 the IWC has had the stated intent of setting the catch limits below the sustainable yields as calculated by continuing assessments. At that time the catch limits for the Antarctic baleen whale were set in terms of Blue Whale Units (BWU). One BWU equalled 1 blue whale, 2 fin whales, $2 \frac{1}{2}$ humpbacks or 6 sei whales. These values were based on the relative oil yields of the different species, but the system was unfortunate because it took no account of the fact that each species may need a different degree of protection. The same criticism can also be levelled at the idea of a total moratorium on whaling, for not all whale stocks require such protection.

Catches of whales in the North Pacific have always been limited on a species basis, and from 1972 the Antarctic catch limits have also been set species by species. An even finer degree of control would be achieved by regulating the breeding stocks independently, but these cannot yet be fully identified. As a move in this direction, though, the IWC has now subdivided the Antarctic into three areas, and imposed maximum catches for each species in each of these areas.

Sperm whales, the largest of the toothed whales, did not come into the BWU system. In 1972 the Scientific Committee recommended that the catches of this species should be limited by each sex separately. This is practicable because the male sperm whales grow considerably larger than the females. The females had been protected from much catching by a minimum size limit. The Scientific Committee therefore also recommended that this size limit should be reduced, so that more females could be caught to bring the sexes into better balance. This is reasonable with the total catch limits imposed, which include a subdivision of the Southern Hemisphere into three areas with separate limits for the sexes in each.

The overall catch limits set this year are summarised in the Table, together with the estimates of sustainable yields. It is apparent from all this evidence that

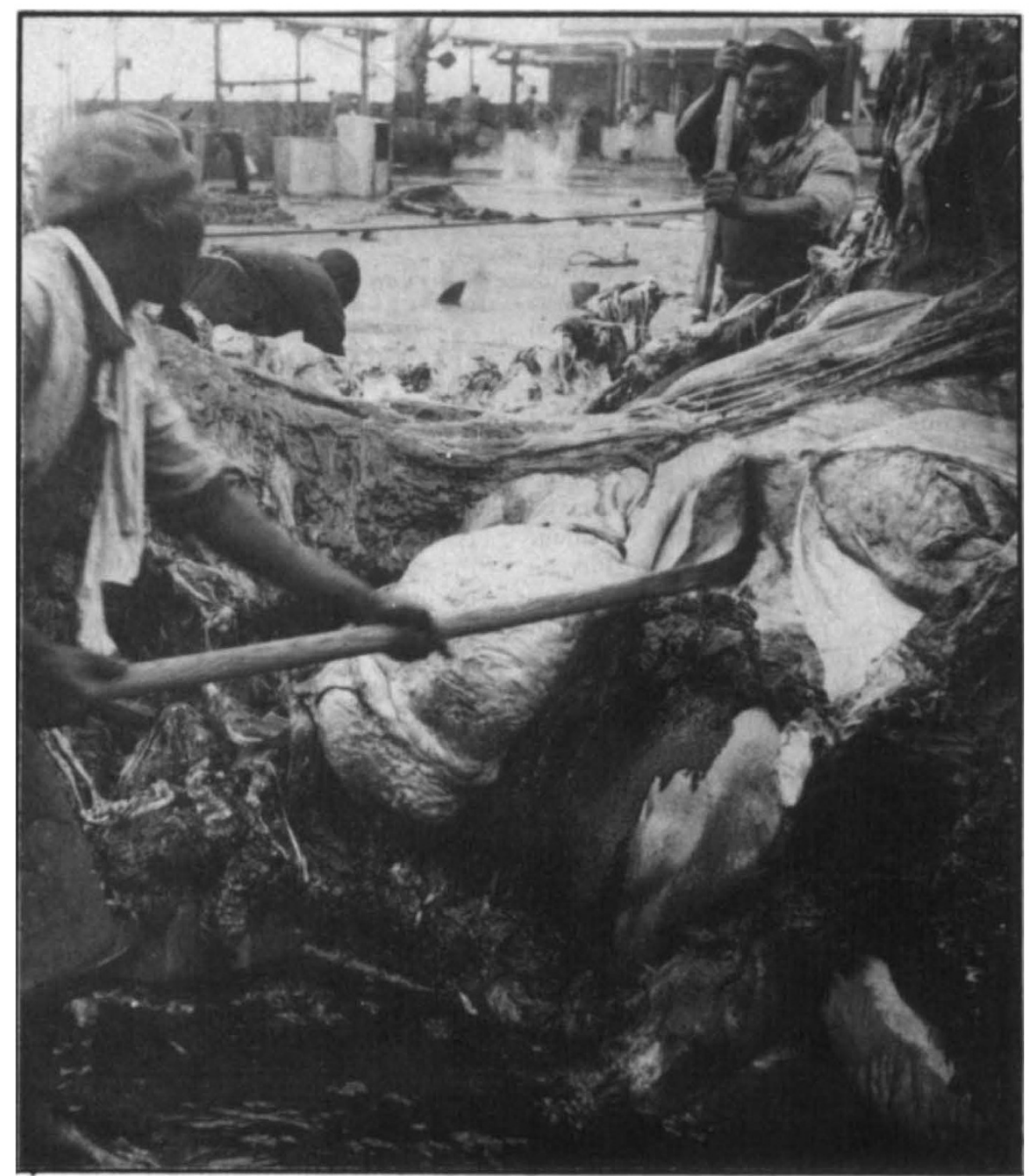

the catches will not cause any species to be in danger of becoming extinct. Even the fin whale. which is the most reduced of the major species still hunted, should be rebuilding slowly. In addition, the IWC is committed to stop the capture of all fin whales in these two regions at least by 1976 , so that the populations will then increase at the maxmimum rate possible.

The Scientific Committee will hold a special meeting to consider the assessment and status of all whale stocks in time to advise the commission next year on these matters. In addition, it will put forward detailed plans for extensive monitoring and research on the stocks. It is hoped that the costs of these projects, running into several millions of pounds, will be met by the United Nations (UN) Environment Programme, the UN Food and Agri-

cultural Organisation and other similar agencies.

There is much research needed. Up to the present, each whale species has been considered in isolation, without regard to the other whale species or the rest of the environment. Evidence of interactions is now becoming available. In addition, concepts involving the biomass of whales rather than their numbers will require study before they can be incorporated into the sustainable yield models already employed.

At all events, the future for the whales looks bright. There is no danger of any of them disappearing through overexploitation under the present controls, and there is the prospect of management being grounded on rational policies designed to provide the greatest long term benefit from this considerable natural resource of the oceans.

Overall catch limits set by the IWC and the estimated present sustainable yields of the whale populations

\begin{tabular}{lrrrr} 
& & Antarctic & \multicolumn{2}{c}{ North Pacific } \\
Fin & Quota & SY & Quota & $750-900$ \\
Sei & 1,000 & 3,200 & 300 & 2,500 \\
Minke & 4,000 & 5,200 & 2,000 & $-1,200$ \\
Sperm* & 7,000 & $7-12,000$ & 6,000 & 6.200 \\
\hline
\end{tabular}

*Whole Southern hemisphere. 